\title{
Treatment of pain in chronic pancreatitis by inhibition of pancreatic secretion with octreotide
}

\author{
P Malfertheiner, D Mayer, M Büchler, J E Domínguez-Muñoz, B Schiefer, H Ditschuneit
}

University Hospital of

Bonn, Germany

P Malfertheiner

J E Domínguez-Muñoz

Departments of

Internal Medicine

D Mayer

B Schiefer

H Ditschuneit

and General Surgery M Büchler

University Hospital of Ulm, Germany

Correspondence to: Professor Dr P

Malfertheiner, Medizinische Universitätsklinik

Magdeburg, Leipziger Str

44, B-39120, Magdeburg,

Germany.

Accepted for publication

15 July 1994

Keywords: chronic pancreatitis, pain, pancreatic secretion, octreotide.

Pain is the leading symptom in chronic pancreatitis, and presents a heterogeneous pattern ranging from a few relapses per year to continuous pain. ${ }^{12}$ In most of the patients onset of chronic pancreatitis is characterised by an episode of acute abdominal pain, often with all the features of acute pancreatitis. As the disease progresses, pain attacks become more frequent, but persistent pain, which requires continuous analgesic treatment is seen in only around 10 to $20 \%$ of patients. ${ }^{3}$ Only in the advanced stage of chronic pancreatitis, with complete fibrosis of the gland and steatorrhea, may pain eventually disappear.

\begin{abstract}
Department of
Internal Medicine-

Gastroenterology,

Abstract

It has been suggested that pancreatic ductal hypertension, secondary to pancreatic outflow obstruction, is a cause of pain in chronic pancreatitis. This study investigated the effect of inhibiting pancreatic secretion with octreotide in chronic pancreatitis pain. Ten patients with chronic alcoholic pancreatitis and severe daily pain were included in an intraindividual double blind crossover study. All patients received octreotide $(3 \times 100 \mu \mathrm{g} / \mathrm{day}$ subcutaneously) and placebo $(3 \times 0.9 \%$ saline solution subcutaneously) for three days at random. Between both treatment phases a two day washout period was interposed. Intensity of pain (visual analogue scale) and analgesic consumption were carefully registered. Pancreatic secretion was monitored daily by measuring faecal chymotrypsin concentration. It was found that during the administration of octreotide, pancreatic secretion was strongly inhibited (faecal chymotrypsin mean (SD) $1.7(0.6) \mathrm{U} / \mathrm{g})$ with respect to placebo $(9.6(4 \cdot 2) \mathrm{U} / \mathrm{g})$ and washout $(7.6$ $(3 \cdot 1) \mathrm{U} / \mathrm{g})$ periods $(\mathbf{p}<0 \cdot 001)$. Pain score $(29.6(4.5) v 28 \cdot 7(5 \cdot 8))$ and consumption of analgesics were no different during the octreotide and placebo periods. It is concluded that short term inhibition of pancreatic secretion does not result in pain relief in patients with chronic pancreatitis. This finding is in contrast with the hypothesis that outflow obstruction of pancreatic secretion with consequent ductal hypertension is an important cause of severe persistent pain in chronic pancreatitis.

(Gut 1995; 36: 450-454)
\end{abstract}

Relapsing as well as continuous pain in chronic pancreatitis vary considerably concerning localisation, irradiation, and temporal relation with food intake. This heterogeneity may explain why several different hypotheses have been proposed to explain the pathogenesis of pain in chronic pancreatitis.

Two mechanisms are commonly suggested for the generation of pain in chronic pancreatitis. These are ductal and parenchymal hypertension, ${ }^{4-6}$ and inflammatory parenchymal changes with participation of pancreatic nerves. ${ }^{78}$ According to these hypotheses, therapeutic procedures for pain in chronic pancreatitis have focused on decompression of the hypertensive ductal/parenchymal structures or on resection of the inflammatory mass. ${ }^{910} \mathrm{~A}$ therapeutic approach of decreasing ductal hypertension has been more recently attempted by high doses of exogenous pancreatic enzymes. ${ }^{11} 12$ As exogenous pancreatic enzymes inhibit pancreatic secretion by a negative feedback, pain relief is expected to occur in cases with increased intraductal and parenchymal pressure. Most therapeutic studies, however, failed to give credit to this rationale or provided inconclusive data. ${ }^{13} 14$ Different doses of exogenous pancreatic enzymes may explain the inconsistency in results among studies, and the lack of control of whether inhibition of pancreatic secretion was achieved in individual patients leaves this issue unsettled.

To further contribute to the understanding of the pathogenesis and treatment of pain in chronic pancreatitis, we tested the role of ductal hypertension by giving a potent inhibitor of pancreatic secretion, the somatostatin analogue octreotide. ${ }^{15} 16$ We hypothesised that by inhibiting pancreatic secretion and, as a consequence, decreasing intraductal pressure, pain relief should occur if this mechanism is operating. Thus, we could identify those patients who would eventually respond favourably to endoscopic or surgical pancreatic decompression. For this study, we selected patients who had well defined chronic pancreatitis and severe pain daily, as patients with relapsing pain would require long periods of observation and treatment and may not guarantee a high enough compliance.

\section{Methods}

The study was conducted as an intraindividual double blind crossover study. The study design was approved by a local ethics committee and consent was obtained from all patients. From September 1990 until March 1992, 56 patients 
TABLE I Clinical characteristics of patients

\begin{tabular}{|c|c|c|c|c|c|c|c|c|c|}
\hline Patient & Age & Sex & Aetiology & $\begin{array}{l}\text { Duration of } \\
\text { CP from } \\
\text { onset of } \\
\text { symptoms (y) }\end{array}$ & $\begin{array}{l}\text { Duration of } \\
\text { CP from } \\
\text { time of } \\
\text { diagnosis (y) }\end{array}$ & $\begin{array}{l}\text { ERP } \\
\text { stage }\end{array}$ & $\begin{array}{l}C T \\
\text { stage }\end{array}$ & $\begin{array}{l}\text { US } \\
\text { stage }\end{array}$ & $\begin{array}{l}P L T \\
(\mu g /)\end{array}$ \\
\hline 1 & 55 & Male & Alcohol & 12 & 10 & 2 & & 2 & $5 \cdot 6$ \\
\hline 2 & 52 & Male & Alcohol & 22 & 9 & 3 & 3 & 3 & 0.96 \\
\hline 3 & 42 & Male & Alcohol & 15 & 2 & 3 & 3 & 3 & 1.07 \\
\hline 4 & 34 & Male & Alcohol & 10 & 10 & 3 & 3 & 3 & 3.01 \\
\hline 5 & 31 & Male & Alcohol & 9 & 7 & 3 & & 3 & $2 \cdot 8$ \\
\hline 6 & 56 & Male & Alcohol & 8 & 4 & 3 & 2 & 3 & 2.53 \\
\hline 7 & 42 & Male & Alcohol & 11 & 4 & 3 & 3 & 2 & $1 \cdot 27$ \\
\hline 8 & 41 & Male & Alcohol & 5 & 2 & 1 & & 1 & 3.6 \\
\hline 9 & 45 & Male & Alcohol & 8 & 5 & 3 & 3 & 3 & $1 \cdot 21$ \\
\hline 10 & 62 & Male & Alcohol & 10 & 3 & 3 & 3 & 3 & $2 \cdot 17$ \\
\hline
\end{tabular}

$\mathrm{CP}=$ chronic pancreatitis; $\mathrm{ERP}=$ endoscopic retrograde pancreatography $\mathrm{CT}=$ computed tomography; US=ultrasonography; PLT = serum pancreolauryl test; normal value $\geqslant 4.5 \mu \mathrm{g} / \mathrm{l}$.

with chronic pancreatitis required medical consultations for abdominal pain. Patients were enroled in the study only if they had experienced severe pain daily within the last four weeks and if the use of analgesic treatment was necessary at least once a day. Fifteen patients with chronic pancreatitis fulfilled these clinical requirements.

The following criteria were required for final admission to this study: (a) Diagnosis of chronic pancreatitis was based on clinical history and unequivocal pathognomonic changes in the endoscopic retrograde pancreatography (ERP) according to the classification of Cambridge. ${ }^{17}$ In addition, pancreatic function was assessed, in all patients, by pancreolauryl serum test. ${ }^{18}$ The stage of chronic pancreatitis was graded by ERP and computed tomography, according to criteria previously described. ${ }^{19}$ Ultrasound criteria were used in analogy to criteria used for computed tomography. ${ }^{19}$ (b) No previous pancreatic or gastrointestinal surgery. (c) Absence of chronic pancreatitis complications, bile duct compression, duodenal stenosis or a pancreatic cyst larger than $2 \mathrm{~cm}$. (d) Absence of pancreatic anatomic anomalies. (e) Absence of other disorders in the upper gastrointestinal tract (peptic ulcer disease, reflux oesophagitis, gastric neoplasias, etc) as assessed by gastroduodenoscopy. (f) No liver or biliary disorders were detected by ultrasound or biochemical parameters.

As a result of these criteria, two of 15 patients had to be excluded: one patient had previous gastric surgery, and the second patient had pancreas anulare in addition to chronic pancreatitis.

All patients included were asked to stop alcohol intake two weeks before the study. All the patients, except two, had completely stopped drinking within the period. No patient was receiving continuous analgesic treatment for more than three months. Patients were also requested to register analgesic consumption over the two weeks before the study. A further three patients were excluded at the start of the study because they did not require analgesic treatment for an entire day during a two day observation period before the study. After this careful selection, 10 male patients (mean age 46 years, range 31-62) completed the study and were included in the final evaluation. None of these patients had insulin dependent diabetes; two patients had type II diabetes, and three had an abnormal glucose tolerance test. None of the patients had malnutrition. Four patients had pancreatic stones in the main pancreatic duct with partial obstruction to the pancreatic outflow. Table I shows the demographic data and diagnostic staging of each individual patient. During the entire study, patients received a standardised diet (carbohydrates $60 \%$, protein $25 \%$, fat $15 \%$; $30 \mathrm{kcal} / \mathrm{kg}$ body weight). The proportion of dietary carbohydrates was chosen because pancreatic enzyme supplementation was stopped for all patients. Patients had no access to alcohol during the study.

\section{STUDY DESIGN}

Before starting treatment, patients received a pain protocol and were carefully instructed how to register pain on an ordinary scale. The scale on this protocol included five categories of pain intensity, $1=$ no, $2=$ slight, $3=$ moderate, $4=$ severe, $5=$ severe pain requiring analgesics. Patients were requested to record the level of pain they experienced every hour except during the hours of sleep. During the day the patients were interviewed every four hours and their scales were checked to ensure they had registered their pain. On the protocol all analgesics required by the patients were recorded. As some patients, before entering the study, were receiving tilidin $\mathrm{HCl} 50 \mathrm{mg}$ combined with naloxone $4 \mathrm{mg}=0.72 \mathrm{ml}$ equivalent to 20 drops (Valoron N, purchased from Gödecke) some were receiving tramadol $\mathrm{HCl}$ $50 \mathrm{mg}=1 \mathrm{ml}$ equivalent to 20 drops therapy (Tramal purchased from Grünenthal), they maintained their usual analgesic drugs, on request, during the study period. The amount of analgesic treatment required was recorded as drop number per day.

Patients remained in hospital during the study. After a two day observation period patients were randomly allocated to an intraindividual crossover treatment with octreotide and placebo for three days. Octreotide $100 \mu \mathrm{g}$ and placebo (saline solution $0.9 \%$ ) were subcutaneously injected every eight hours. Between the two different treatments, a washout period of two days was included. Four patients with main pancreatic duct lithiasis continued the treatment with octreotide $(3 \times 100 \mu \mathrm{g} /$ day subcutaneous) for two $(n=2)$ or three months $(n=2)$.

Blood and faecal samples were taken every morning for determination of serum amylase, pancreatic amylase, trypsin and lipase, and faecal chymotrypsin. Serum amylase was measured by an enzymatic method using $p$-Nitrophenyl- $\alpha$, D-maltoheptaoside as substrate (Monotest Amylase, Boehringer Mannheim Diagnostica, Germany). Serum pancreatic isoamylase activity ( $P$-amylase) was determined by means of the wheat inhibition method (Phadebas Isoamylase Test, Pharmacia Diagnostic, Uppsala, Sweden). Serum trypsin concentration was measured by radioimmunoassay (RIA-gnost-Trypsin, Behringwerke AG, Marburg, Germany). Specific serum pancreatic lipase concentration was measured by 

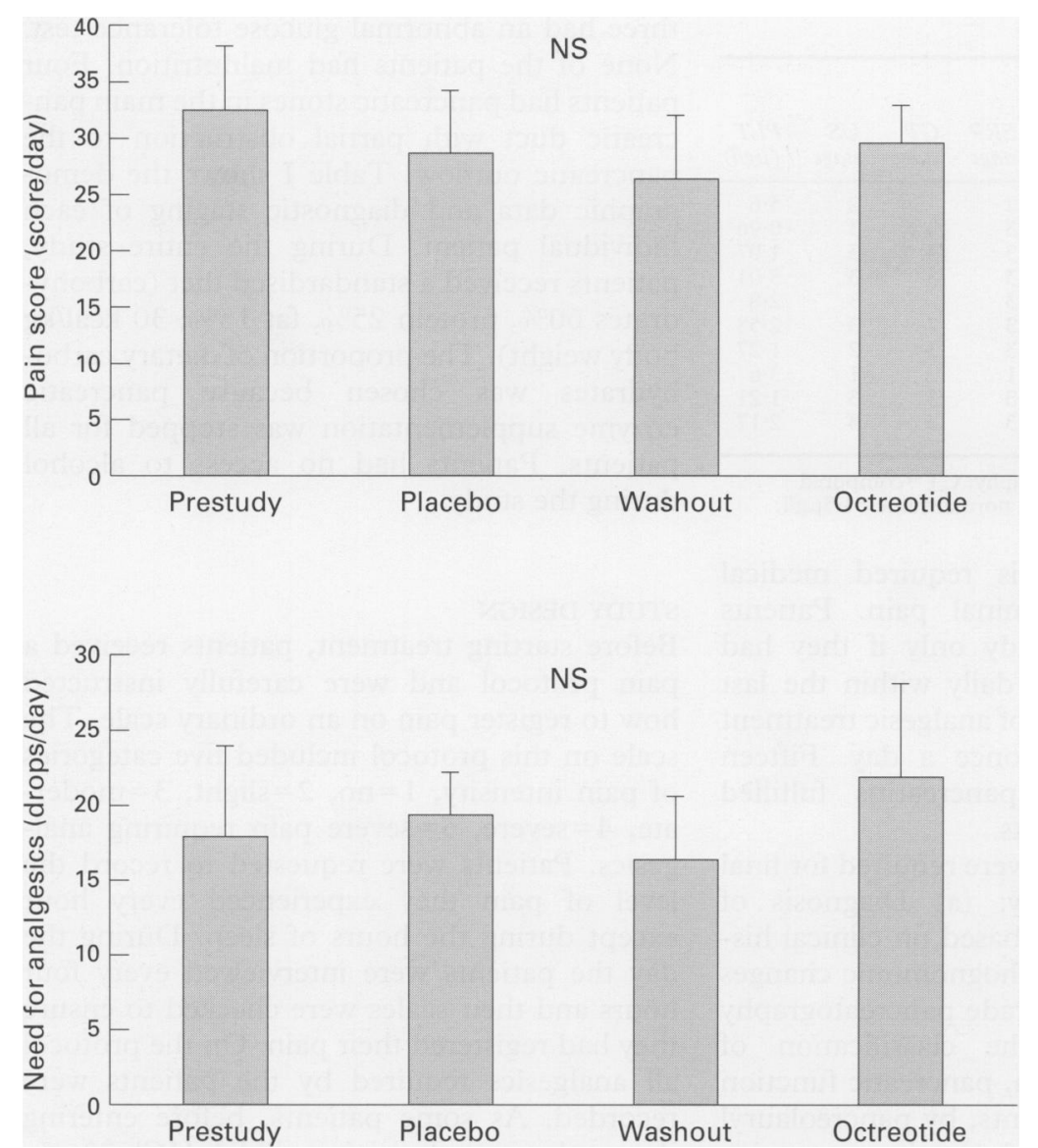

Figure 1: Pain score (score/day) and need for analgesics (drops/day) in patients with chronic pancreatitis during the different study periods.

enzyme immunoassay (Enzygnost-Lipase, Behringwerke AG, Marburg, Germany). Faecal chymotrypsin was measured by a colorimetric method using Succ-Ala-Ala-Pro-Phe-pNitroanilin as substrate (Monotest Chymotrypsin, Boehringer Mannheim Diagnostica, Germany).

\section{DATA ANALYSIS}

Pain intensity was expressed as the sum of all the scores recorded each day. Results were expressed as mean (SD). Differences of pain intensity, need for analgesics, serum pancreatic enzymes, and faecal chymotrypsin according to the treatment phase (prestudy, octreotide, placebo) were evaluated by repeated measures of one way analysis of variance (ANOVA).

\section{Results}

None of the patients experienced any adverse effect during the study. The weight of individual patients was kept constant by the special diet despite strong inhibition of pancreatic secretion during the octreotide phase. Bowel movements were not increased (mean two a day) except in two patients (three a day) during the period of octreotide treatment. Two patients receiving longterm octreotide developed cholecystolithiasis.

PAIN INTENSITY AND NEED FOR ANALGESICS Pain pattern varied among patients. Two of them experienced the most severe pain two to three hours after meals, four patients had maximum pain during the night, and four had an absolutely irregular pain cycle. Intensity of pain was no different in either the prestudy, placebo or octreotide treatment phase (Fig 1). There was also no reduction in the requirement of analgesics during treatment with octreotide compared with placebo (Fig 1). There was, however, a reduction in the consumption of analgesics during each of the days in hospital compared with the consumption of analgesics at home (20 (10) drops $v 40$ (10) drops, respectively, $\mathrm{p}<0.01)$. No therapeutic benefit with octreotide was seen when patients with postprandial pain were separately analysed. In the subgroup of patients with main pancreatic duct stones, no benefit was obtained by prolonged octreotide treatment.

\section{PANCREATIC FUNCTION}

Faecal chymotrypsin was significantly inhibited in all patients during the three days of octreotide treatment (Fig 2). Faecal chymotrypsin concentrations during octreotide treatment $(1.69(0.58) \mathrm{U} / \mathrm{g})$ pointed to an almost complete absence of pancreatic secretion. There was no influence of octreotide on basal serum concentrations of pancreatic enzymes after an overnight fast (Table II).

\section{Discussion}

This study showed that strong inhibition of pancreatic secretion obtained by treatment with octreotide $(3 \times 100 \mu \mathrm{g} /$ day $)$ does not influence severe pain in chronic pancreatitis. In the short term, octreotide in the dose used was previously shown to inhibit pancreatic secretion by $80 \%$ in healthy volunteers. ${ }^{16}$ The almost complete abolishment of pancreatic secretion as shown by the measurement of faecal chymotrypsin is, by physical law, accompanied with a drop in intraductal pressure. The lack of pain improvement by inhibiting pancreatic secretion seems to be a strong argument against theories that support a role of increased ductal and parenchymal pressures in the pathogenesis of pain in chronic pancreatitis. ${ }^{4-6}$ 1112 This finding is in contrast with two previous studies, in which surgical decompression of the ductal system was followed by a reduction in ductal and intraparenchymal pressure and an improvement in pain. ${ }^{56}$ Both of these studies, however, do not permit differentiation

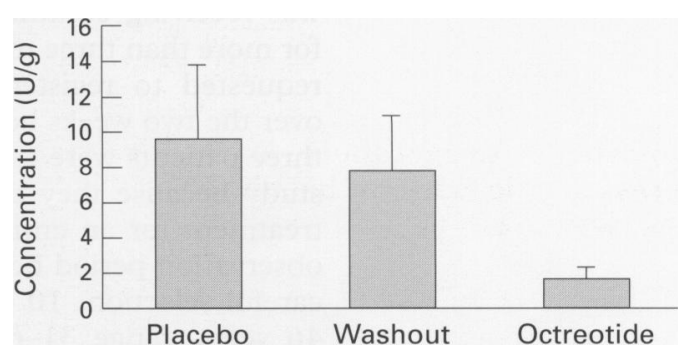

Figure 2: Faecal chymotrypsin concentrations (mean (SD)) in patients with chronic pancreatitis during the different study periods. 
TABLE II Serum pancreatic enzyme concentrations (mean (SD)) over the different study periods

\begin{tabular}{llll}
\hline & Placebo treatment & Washout & Octreotide treatment \\
\hline Total amylase $(\mathrm{u} / \mathrm{l})$ & $300 \cdot 5(47 \cdot 2)$ & $289 \cdot 6(50 \cdot 7)$ & $312 \cdot 1(53 \cdot 3)$ \\
P-amylase $(\mathrm{u} / \mathrm{h})$ & $190 \cdot 4(51 \cdot 7)$ & $177 \cdot 8(49 \cdot 5)$ & $174 \cdot 0(46 \cdot 1)$ \\
Trypsin $(\mathrm{ng} / \mathrm{ml})$ & $647 \cdot 3(161 \cdot 0)$ & $680 \cdot 3(149 \cdot 2)$ & $633 \cdot 0(141 \cdot 0)$ \\
Lipase $(\mathrm{ng} / \mathrm{ml})$ & $119 \cdot 1(42 \cdot 6)$ & $116 \cdot 4(37 \cdot 5)$ & $121 \cdot 5(30 \cdot 9)$ \\
\hline
\end{tabular}

Reference values: total amylase $<380 \mathrm{u} / \mathrm{l}$; P-amylase 40-240 u//; trypsin 80-240 ng/ml; lipase $8-54 \mathrm{ng} / \mathrm{ml}$.

between the effect of ductal decompression and the non-specific effects of pancreatic surgery. Simply dissecting nerves during surgery could account for the therapeutic effect.

By analysing individual patients with either postprandial pain (when secretion and duct pressure are expected to be maximal), or patients with stones in the main pancreatic duct and apparent ductal obstruction, we again did not see any therapeutical benefit during octreotide treatment.

Several studies that aimed at investigating the relation of pancreatic function and the degree and type of morphological pancreatic changes in imaging procedures with the degree of pain did not find any correlation. ${ }^{20-24}$ Abolishment of pain may be achieved in a terminal stage of chronic pancreatitis with an almost complete absence of pancreatic secretion, as shown in several studies by Ammann et $a .^{23}$ At this stage, however, the pancreatic gland is completely fibrotic and the inflammatory activity is greatly reduced or even absent. The findings of this study favour the assumption that chronic pain is probably generated by the inflammatory process within the pancreas and the peripancreatic region. ${ }^{7}$

The strict inclusion of patients with daily and severe pain in our study and not of patients with sporadic bouts of pain could be used as an argument for the therapeutic ineffectiveness obtained by the inhibition of pancreatic secretion. Daily pain is certainly less frequent than relapsing pain in patients with chronic pancreatitis, as confirmed in this series, continuous pain was present in 15 of 56 cases (27\%). Daily pain requires a pathogenetic mechanism that is always present, however, and this could be either chronic inflammation or ductal obstruction. If duct obstruction plays a part in the pathogenesis of pain in these cases, a therapeutic benefit should be obtained by inhibiting pancreatic secretion. Clinical findings give further evidence to oppose the pain hypothesis of ductal hypertension. Postprandial pain is not a dominant feature of pain in chronic pancreatitis and secretincaerulein in high doses, as used for pancreatic function testing, rarely elicits pain in patients with chronic pancreatitis.

These arguments challenge more recent data showing significant pain relief after interventional endoscopic procedures in which a stent was placed in, or stones removed from, the main pancreatic duct. ${ }^{25-27}$ In the absence of proper controls, the effect of such endoscopic interventions cannot be defined as causal for pain relief. If duct obstruction is the cause of chronic pain in chronic pancreatitis then patients with stones in the main pancreatic duct should respond with relief of symptoms to a treatment that inhibits pancreatic secretion. Such a procedure could help to identify those patients who would eventually respond favourably to an endoscopic or surgical drainage procedure and may be worthwhile testing in a future trial.

Dependency on analgesic drugs could account for the lack of therapeutic benefit in some of our patients. The fact that all but two patients could at least temporarily stop drinking and that the analgesic drugs had not been taken for more than three continuous months, with periods of intermission, may reduce the strength of this argument.

The finding that prolonged treatment with octreotide in four patients with chronic pancreatitis and stones in the main pancreatic duct failed to relieve pain is a further, though weaker, argument against the theory of ductal hypertension in the pathogenesis of pain. Prolonged treatment with octreotide has been reported to lead to pain relief in some patients with chronic pancreatitis, ${ }^{28} 29$ but it is questionable whether the inhibitory effect of pancreatic secretion may persist over time because of the reported tachyphylaxis of the drug. ${ }^{30}$ Whether mechanisms other than inhibition of pancreatic secretion may account for the effect of octreotide in relieving pain on a longterm basis and whether the length of treatment should be extended is worthwhile testing in differently designed intervention studies.

In summary, the subset of patients with chronic permanent or severe daily pain has no benefit from short term treatment with octreotide. This finding does not support the hypothesis of ductal hypertension as a cause of pain in those patients with chronic pancreatitis. Whether patients with relapsing pain may benefit from octreotide has to be tested in a study using longterm octreotide treatment.

1 DiMagno EP, Clain JE. Chronic pancreatitis. In: Go VLW, Gardner J, Brooks FP, Lebenthal E, Dimago EP, Scheele GA, eds. The exocrine pancreas: biology, pathobiology and GA, eds. The exocrine pancreas: biology, pathobiolog
diseases. New York: Raven Press, 1986: 541-75.

2 Ammann R, Akovbiantz A, Largiader F, Schueler G. Course and outcome of chronic pancreatitis. Gastroenterology 1984; 86: 820-8.

3 Ammann R, Buehler H, Muench R, Freiburghans A, Siegenthaler $W$. Differences in the natural history of idiopathic (non-alcoholic) and alcoholic chronic pancreatitis. Pancreas 1987; 2: 368-77.

4 Ebbehoj N, Borly L, Bülow J, Henriksen JH, Heyeraas KJ, Rasmussen SG. Evaluation of pancreatic tissue fluid pressure measurements intraoperatively and by sonographically guided fine-needle puncture. Scand $\mathcal{f}$ Gastroenterol 1990; 25: 1097-102.

5 Okazaki K, Yamamoto Y, Ito K. Endoscopic measurement of papillary sphincter zone and pancreatic main duct presof papillary sphincter zone and pancreatic main duct pres-
sure in patients with chronic pancreatitis. Gastroenterology sure in patients with

6 Ebbehoj N, Borly L, Bülow J, Rasmussen SG, Madsen P. Evaluation of pancreatic tissue fluid pressure and pain in chronic pancreatitis: a longitudinal study. Scand $\mathcal{f}$ Gastroenterol 1990; 25: 462-6.

7 Bockman DE, Büchler M, Malfertheiner P, Beger HG. Analysis of nerves in chronic pancreatitis. Gastroenterology 1988; 94: 1459-69.

8 Büchler M, Weihe E, Frieß H, Malfertheiner P, Bockman $\mathrm{BE}$, Müller S, et al. Changes in peptidergic innervation in chronic pancreatitis. Pancreas 1992; 7: 183-92.

9 Malfertheiner P, Büchler M. Indications for endoscopic or surgical therapy in chronic pancreatitis. Endoscopy 1991; 23: $185-90$.

10 Frey CF, Smith JG. Description and rationale of a new operation for chronic pancreatitis. Pancreas 1987; 2: 701-7. 
11 Isaksson G, Ihse I. Pain reduction by an oral pancreatic enzyme preparation in chronic pancreatitis. Dig Dis Sci 1983; 28: 97-102.

12 Slaff J, Jacobson D, Tillman CR, Curlington C, Toskes P. Protease-specific suppression of pancreatic exocrine secretion. Gastroenterology 1984; 87: 44-52.

13 Halgreen H, Pedersen TN, Worning H. Symptomatic effect of pancreatic enzyme therapy in patients with chronic pancreatitis. Scand F Gastroenterol 1986; 21 : 104-8.

14 Mössner J, Secknus R, Meyer J, Niederau C, Adler G. Treatment of pain with pancreatic extracts in chronic pancreatitis: results of a prospective placebo-controlled multicenter trial. Digestion 1992; 53: 54-66.

15 Köhler E, Beglinger C, Dettwiler S, Whitehouse I, Gyr K. Effect of a new somatostatin analogue on pancreatic function in healthy volunteers. Pancreas 1986; 1: 154-9.

16 Kemmer TP, Malfertheiner P, Büchler $M$, Frieß $H$, Meschenmoser L, Ditschuneit $H$. Inhibition of human exocrine pancreatic secretion by the long-acting somatoexocrine pancreatic secretion by the long-acting somato-
statin analogue octreotide (SMS 201-995). Aliment Ptatin analogue octreotide (SMacol Ther 1992; 6: 41-50.

17 Axon ATR, Classen M, Cotton PB, Cremer M, Freeny PC, Less WR. Pancreatography in chronic pancreatitis: international definitions. Gut 1984; 25: 1107-12.

18 Malfertheiner P, Büchler M, Müller A, Ditschuneit $H$. Fluorescein dilaurate serum test: a rapid tubeless pancreatic function test. Pancreas 1987; 2: 53-60.

19 Malfertheiner P, Büchler M, Stanescu A, Ditschuneit $H$. Exocrine pancreatic function in correlation to ductal and parenchymal morphology in chronic pancreatitis. parenchymal morphology in chronic
Hepatogastroenterology 1986; 33: 110-4.

20 Malfertheiner P, Büchler M, Stanescu A, Ditschuneit $H$. Pancreatic morphology and function in relationship to pain in chronic pancreatitis. Int $\mathcal{F}$ Pancreatol 1987; 1: 59-66.

21 Bornman PC, Marks IN, Girdwood AH, Clain JE Narumsky L, Clain DJ, et al. Is pancreatic duct obstruction or stricture a major cause of pain in calcific pancreatitis. Br $\mathcal{F}$ Surg 1980; 76: 425-8.
22 Jensen AR, Matzen P, Malchow-Moller A, Christoffersen I. The Copenhagen Pancreatitis Study Group. Pattern of pain, duct morphology, and pancreatic function in chronic pancreatitis. Scand $f$ Gastroenterol 1984; 19: chronic

23 Girdwood AH, Bornman PC, Marks IN. Ductal morpology and pain in chronic alcohol-induced pancreatitis. In: Beger HG, Büchler M, Ditschuneit $H$, Malfertheiner $P$, eds. Chronic pancreatitis. Berlin: Springer-Verlag, 1990: 218-20.

24 Malfertheiner P, Pieramico O, Büchler M, Ditschuneit H. Relationship between pancreatic function and pain in chronic pancreatitis. Acta Chir Scand 1990; 156: 267-71.

25 Sauerbruch T, Holl J, Sackmann M, Paumgartner G. Extracorporeal lithotripsy of pancreatic stones in patients with chronic pancreatitis and pain: a prospective follow up study. Gut 1992; 33: 969-72.

26 Delhaye $M$, Vandermeeren A Baize $M$, Cremer $M$ Extracorporeal shock-wave lithotripsy of pancreatic calculi. Gastroenterology 1992; 102: 610-20.

27 Kozarek RA, Patterson DJ, Ball TJ, Traverso LW. Endoscopic placement of pancreatic stents and drains in the management of pancreatitis. Ann Surg 1989; 209: 261-6.

28 Schmalz MJ, Soergel KH, Johanson JF. The effect of octreotide acetate on the pain of chronic pancreatitis. Gastroenterology 1992; 102: A290.

29 Lambiase LR, Forsmark C, Jadunandan I. Liddle R, Toskes PP. Correlation of pain relief and reduction in fasting serum CCK levels in chronic pancreatitis patients treated with octreotide. Gastroenterology 1993; 104: A315.

30 Lembcke B, Creutzfeldt W, Schlieser S, Ebert R, Shaw C, Koop I. Effect of the somatostatin analogue Sandostatin (SMS 201-995) on gastrointestinal, pancreatic and biliary function and hormone release in normal men. Digestion 1987; 36: 108-24. 